\title{
Artificial Intelligence: Technology 4.0 as a solution for healthcare workers during COVID-19 pandemic
}

\author{
Mr. Anuj Kumar, Dr. Purvi Pujari, Dr. Nimit Gupta
}

\begin{abstract}
The COVID-19 pandemic has brought unprecedented spotlight to the healthcare sector across the globe. It has revealed the weak links as well as neglected aspects of the healthcare sector. The aspects like data collection about patients, access to and outreach of authentic information in times of pandemics and use of technology for collaboration among medical researchers and workers have been overlooked for a long period of time. As the world is watching an inflection point of the digital technology era, it is highly imperative to analyze where these two supposedly separate sectors converge. This research paper has attempted to do the same. A systematic literature review of twenty research papers have been done to know impact of artificial intelligence in dealing with COVID-19 problem. The benefits offered by the technological revolution, namely technology 4.0, to the healthcare sector has been analyzed in this paper with a special emphasis on the role of Artificial Intelligence. Adoption of latest technology in collating patients handling systems, supply of medicines and other medical requirements, collaboration in the areas of research and development amid COVID-19 are few of the aspects of the paper. There is an immediate need for a technology embedded in healthcare system.
\end{abstract}

Keywords: Technology 4.0, Health Care Sector, COVID-19, Telemedicine, Artificial Intelligence

\section{Introduction - COVID-19 Pandemic}

COVID-19 pandemic has been a cause of lots of death and suffering throughout the world. The escalating number of patients and deaths due to COVID-19 were overwhelming for even the most sophisticated medical infrastructures around the globe. As per World Health Organization (WHO), COVID-19, Global epidemiological report of April'2021, a total of 137,866,311 confirmed cases (World Health Organization, 2020) have been reported globally and 2,965,707 patients died (World Health Organization, 2021). The areas which have been hugely impacted are Europe and USA along with UK. Most of these countries are facing a second wave of the virus now. Asian continent, especially India, has also seen huge number of patients. Most of the developing countries with poor medical infrastructure and lesser number of healthcare workers, are more severely impacted (Singh \& Misra, 2020).

\footnotetext{
A. Kumar, Assistant Professor, Apeejay School of Management, Dwarka, Delhi, e-mail: profanuj15@gmail.com

P. Pujari, Associate Professor, Bharati Vidyapeeth's Institute of Management Studies and Research, Navi Mumbai, Maharashtra, India,e-mail: purvipujari@gmail.com

N. Gupta, Professor, School of Management, The NorthCap University, Gurugram, India e-mail: nimitgupta1981@rediffmail.com
} 


\section{Figure 1}

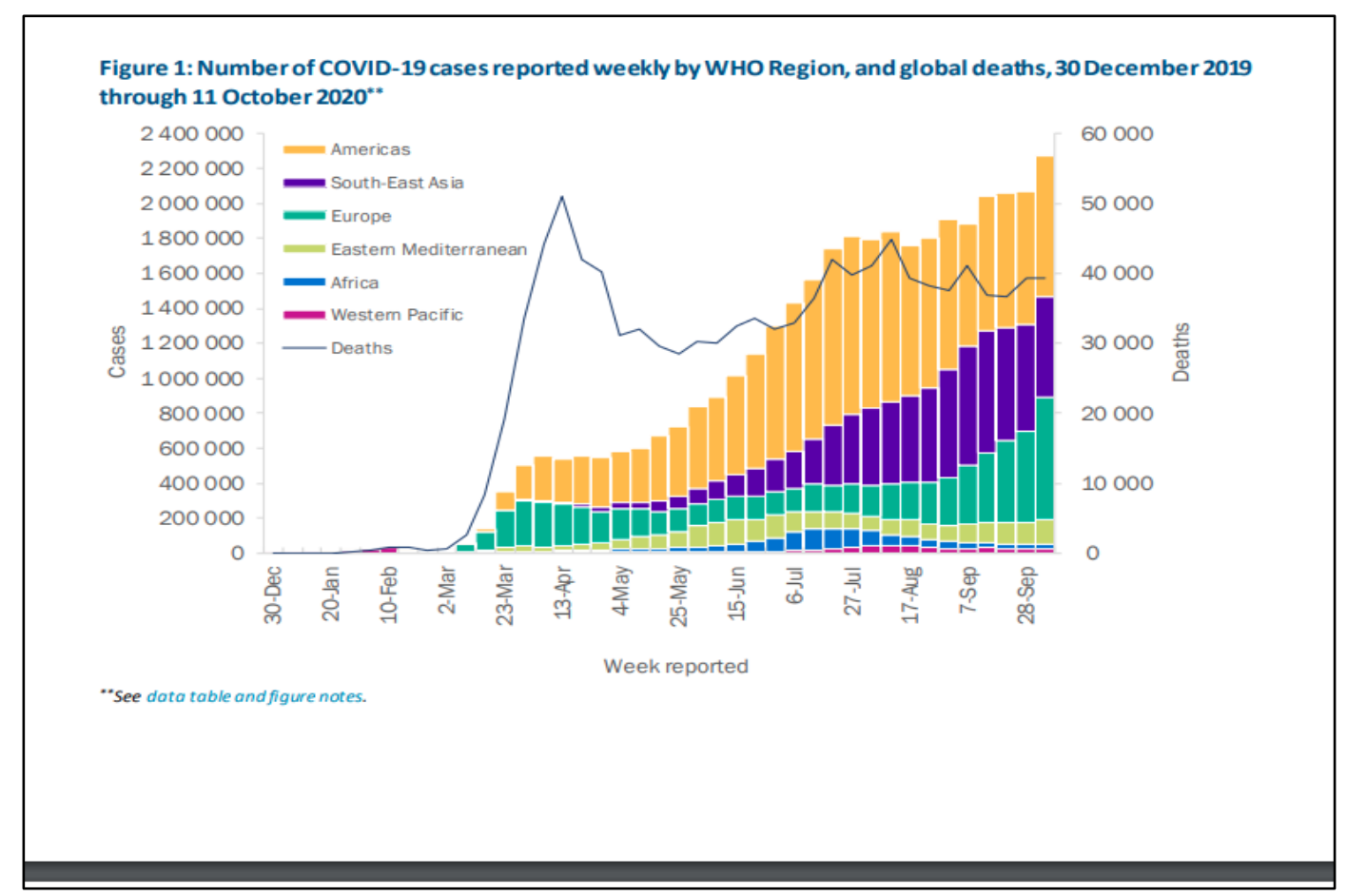

Figure 1 (World Health Organization, 2020)

\section{Table 1}

Table 1. Newly reported and cumulative COVID-19 confirmed cases and deaths, by WHO Region, as of 11 October $2020^{* *}$

\begin{tabular}{|c|c|c|c|c|c|c|}
\hline WHO Region & $\begin{array}{r}\text { New cases } \\
\text { in last } \\
7 \text { days (\%) }\end{array}$ & $\begin{array}{r}\text { Change in } \\
\text { new cases in } \\
\text { last } 7 \text { days }\end{array}$ & $\begin{array}{r}\text { Cumulative } \\
\text { cases (\%) }\end{array}$ & $\begin{array}{r}\text { New deaths } \\
\text { in last } 7 \text { days } \\
(\%)\end{array}$ & $\begin{array}{r}\text { Change in new } \\
\text { deaths in } \\
\text { last } 7 \text { days* }\end{array}$ & Cumulative deaths (\%) \\
\hline Americas & $\begin{array}{r}804735 \\
(35 \%) \\
\end{array}$ & $6 \%$ & $\begin{array}{r}17794771 \\
(48 \%) \\
\end{array}$ & $\begin{array}{r}20509 \\
(52 \%) \\
\end{array}$ & $-5 \%$ & $\begin{array}{r}588867 \\
(55 \%) \\
\end{array}$ \\
\hline South-East Asia & $\begin{array}{r}575763 \\
(25 \%) \\
\end{array}$ & $-6 \%$ & $\begin{array}{r}7911036 \\
(21 \%) \\
\end{array}$ & $\begin{array}{l}7750 \\
(20 \%) \\
\end{array}$ & $-8 \%$ & $\begin{array}{r}126917 \\
(12 \%) \\
\end{array}$ \\
\hline Europe & $\begin{array}{r}694275 \\
(31 \%) \\
\end{array}$ & $34 \%$ & $\begin{array}{r}6918265 \\
(19 \%) \\
\end{array}$ & $\begin{array}{l}6172 \\
(16 \%) \\
\end{array}$ & $16 \%$ & $\begin{array}{r}246709 \\
(23 \%) \\
\end{array}$ \\
\hline $\begin{array}{l}\text { Eastern } \\
\text { Mediterranean } \\
\end{array}$ & $\begin{array}{r}138751 \\
(6 \%) \\
\end{array}$ & $10 \%$ & $\begin{array}{r}2605478 \\
(7 \%) \\
\end{array}$ & $\begin{array}{r}3173 \\
(8 \%) \\
\end{array}$ & $13 \%$ & $\begin{array}{r}66329 \\
(6 \%) \\
\end{array}$ \\
\hline Africa & $\begin{array}{r}29169 \\
(1 \%) \\
\end{array}$ & $11 \%$ & $\begin{array}{r}1227719 \\
(3 \%) \\
\end{array}$ & $\begin{array}{r}991 \\
(3 \%) \\
\end{array}$ & $27 \%$ & $\begin{array}{r}27255 \\
(3 \%) \\
\end{array}$ \\
\hline Western Pacific & $\begin{array}{r}26199 \\
(1 \%) \\
\end{array}$ & $6 \%$ & $\begin{array}{r}651841 \\
(2 \%) \\
\end{array}$ & $\begin{array}{r}633 \\
(2 \%) \\
\end{array}$ & $26 \%$ & $\begin{array}{r}14265 \\
(1 \%) \\
\end{array}$ \\
\hline${ }^{+}$Other & - & - & $\begin{array}{r}741 \\
(<1 \%) \\
\end{array}$ & - & - & $\begin{array}{r}13 \\
(<1 \%) \\
\end{array}$ \\
\hline Global & $\begin{array}{r}2268892 \\
(100 \%) \\
\end{array}$ & $10 \%$ & $\begin{array}{r}37109851 \\
(100 \%) \\
\end{array}$ & $\begin{array}{l}39228 \\
(100 \%) \\
\end{array}$ & $<1 \%$ & $\begin{array}{r}1070355 \\
(100 \%) \\
\end{array}$ \\
\hline
\end{tabular}

"Percent change in the number of newly confirmed cases/deaths in past seven days, compared to seven days prior. Regional percentages rounded to the nearest whole number, glabal totals may not equal $100 \%$.

"see data, table and figure notes 
As per the above data, both developed and developing countries have faced the repercussions of the disease. Most of the countries are now facing a risk of a second wave of the disease (World Health Organization, 2020). The pandemic has created a heavy burden on the health sector. The sheer magnitude of caseloads has resulted in the healthcare sector struggling to keep up with it.

The pandemic has also resulted in learnings for policymakers across the globe in terms of priorities and preparation for a calamity of such magnanimous scale. It has put the spotlight on the poor state of the healthcare sector in both developing and developed countries. The immediate need to coordinate the patients' data-unfolding symptoms, reactions to the medications and possible interventions met an obstacle of connections amongst the healthcare professionals around the world (Neto, et al., 2020). Out of these multiple problems facing the healthcare sector, errors, or mismanagement of diagnosis is a very crucial one.

\section{Healthcare facing issues in diagnosis and tracking}

In a life-threatening situation like a pandemic, accurate and timely diagnosis is very crucial. Subsequent decisions are dependent on the diagnosis. A wrong diagnosis can result in wrong or delayed medication, undue stress, financial costs, and risk of life. The huge number of patients running into thousands and more per healthcare center, increases the pressure on healthcare workers. In a pandemic situation, there are huge possibilities of human errors arising out of human limitations of handling cases which run in thousands. Managing diagnostic accuracy in such times necessitates a need for technological aids. There are quantifiable aspects of diagnosis which can be improved with the help of smart technological intervention. There is also the added significance of opportunities to collate and collaborate across the world. The inclusion of technological tools will be very beneficial to the world (Porter, 2020).

\section{Technology can help in controlling COVID-19}

The above discussion has clearly stated that the condition of hospitals in healthcare segment is going berserk. The authors want to provide a solution for the health care industry in the form of technology. Technology can be helpful in every phase of combating coronavirus pandemic around the whole India (Kumar, et al., 2020). There are different forms of technology which can help hospitals in combating with coronavirus and fasten the response towards the patients. The first problem occurring in front of doctors is related to tracking of corona virus patients. The usage of artificial intelligence as a technology can help in tracking the patients. Indian healthcare segment needs technology to combat pandemic disease like corona. India has only 4.8 practicing doctors per 1000 patients and it will increase to 6.9 till 2030 (Mabiyan, 2018). With one doctor per 1000 patients, it is hard to take proper care of all the patients. Technology could play a vital role. Using artificial intelligence, the doctors can improve their tracking of pandemic cases. Artificial intelligence can help in data prediction and diagnosis of patients. The correct data prediction techniques can help in tracking the patients who are supposed to face the health issues in future. During this pandemic situation, many people are also spreading rumors, artificial intelligence can also help in combating with them. It is possible to integrate artificial intelligence with machine learning tools and then it is easier to decode information from social media platforms by tracking down words which are sensitize or alarming in nature. 


\section{Figure 2}

Artifical Intelligence and Robotics

(For detecting corona cases and fake rumours

Robots can serve as bridge between doctor and patient )

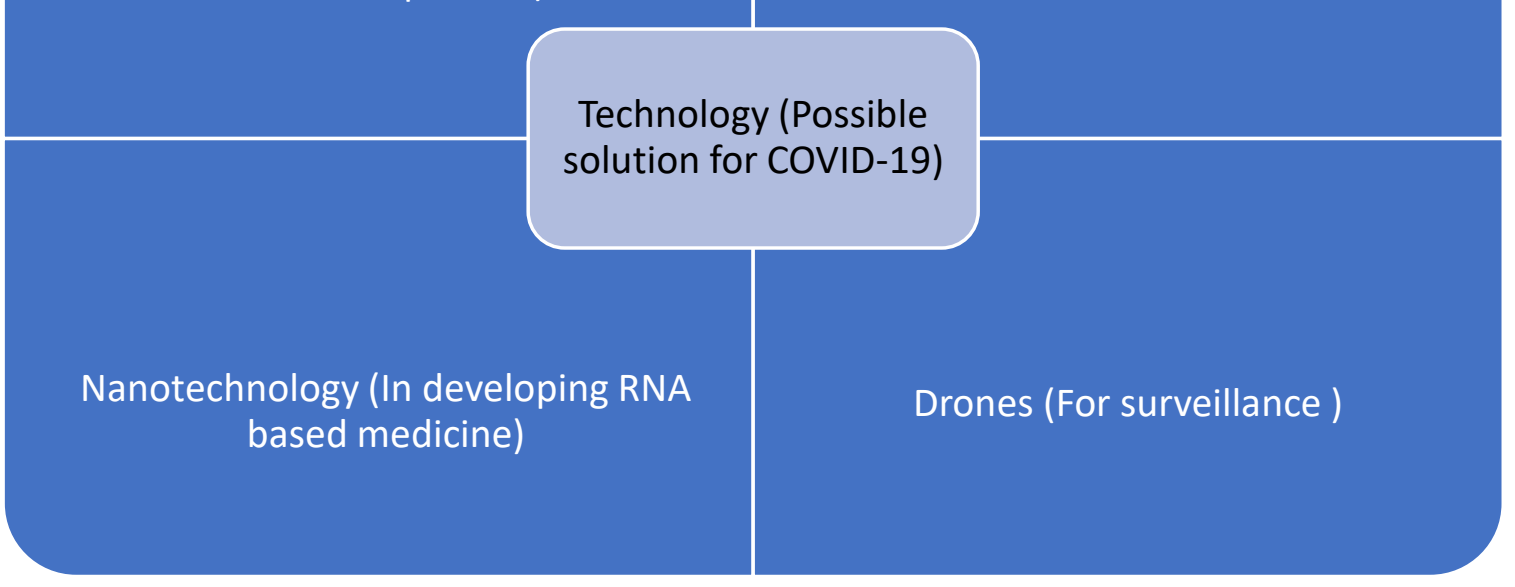

Figure 2 - Technology 4.0 componets as possible solution for COVID-19

The major problem doctors are facing is that they themselves are affected with corona virus disease while treating their patients. Technology can be helpful here, too. With the usage of robotics, the direct physical contact between doctor and corona patients can be minimized or even avoided (Javaid, et al., 2020). Doctors can provide all the necessary patient treatment using robots as the carrier of medical equipment to avoid physical contact. It is needed that the complete human skills are transferred to the robots so that proper diagnosis is possible by robotics mechanism. Technology can also help in maintaining a balance between supply and demand during pandemic situation (Kumar, et al., 2020). Blockchain technology can be helpful in fulfilling the balance between supply and demand. For example, during this pandemic scenario many people are sending donations and other types of funds for the help of coronavirus patients. With the help of blockchain technology, it is possible to track where the funds have been needed and how those donations have been utilized for the treatment of people. As the coronavirus pandemic is spreading around the world, the demand of masks is increasing at global level (Kumar \& Ayedee, 2021). In large countries like India and China, blockchain technology can be used in significant manner to analyze the need of masks and blockchain based platform can help in tracking that need. While using technology, the privacy is a major concern. Blockchain based technology ensures that health records should be maintained confidential without any sharing of data on the privacy of the patient.

At this point of time, decision making is a serious concern for doctors. They are working under huge pressure. Open-source analytical tools can help in decision making of doctors in collective manner because these tools can provide information about ventilators, protein dynamics and the process of protein folding. This software is working on modeling-based technology. It is true that many countries are facing shortage of medical equipment but on many occasions, unawareness also leads to problems. The usage of technology can help in tracking the requirements of resources wherever needed and then, based on real time information, the essential medical equipment can be provided to the patients. Technology can be a gamechanger in accelerating the pace of vaccine development and delivery to COVID-19 patients. 
Nanotechnology played a vital role in preparation of COVID-19 vaccine. Lipid nanoparticles are the vital components of Pfizer and Moderna mRNA COVID-19 vaccines (Tenchov, 2021). The nanoparticles are playing an important role in protecting and transporting mRNA to the right cells. The potential of nanotechnology can be further used in future for preparing more vaccines of COVID-19 (Javaid, et al., 2020). The scientists are already working on developing nanotechnology-based particles to produce more vaccines of COVID-19. There are many containment zones in India which are highly affected by COVID-19. The surveillance of those containment zones is a headache for the government. In Mumbai, many policemen are affected by coronavirus because they were looking after the containment zones. It has been advised that government should manufacture and use drone cameras for surveillance purpose. Though government is already using drone cameras in few areas, more such cameras are required for effective distribution of food and other materials. It is true that technology cannot completely replace people, but it can reduce the burden and chances of COVID-19 spread.

\section{Technology 4.0}

The resulting lockdown after the global pandemic stressed the need of adoption of technological tools by the healthcare sector. There is no better time to adopt the latest medical innovations. Some of the pioneering technological tools help save time, efforts, and most importantly precious lives. Following are briefly described technological interventions that can be adopted in healthcare sector:

1. Virtual Reality: Virtual Reality (VI) had empowered the physicians with its adoption in areas like surgery and medical training. The advantage of virtual reality is that it helps the physicians in understanding and acquiring knowledge about human body through interactions in virtual manner. A Harvard Business Review study showed that VRtrained surgeons could improve their overall performance in multiple categories by $230 \%$ as compared to their traditionally trained counterparts (Blumstein, 2019).

2. Nanotechnology: Nanotechnology has shown promising adoptions in the field of drug delivery, cancer therapy, diagnostics, cell therapy and production of biocompatible materials (Singh, et al., 2020). It is an emerging field where new implementations are being explored the world over. Health care sector will immensely benefit from its offered solutions in the field of diagnosis and treatment of patients through improved and precise medications.

3. Robotics: Robotic surgeries are a wonderful fusion of technology and medicine, giving way to precision, accuracy, and enhanced human skills. Right from exoskeleton to rob buddies, prosthetic limbs, assistance in movement of patients, newer and better uses of robotics are being identified by the medical sector.

4. Artificial Intelligence: Artificial Intelligence (AI) is proving to be the game changer for the health sector. AI can be instrumental in handling huge data in terms of patients' information regarding gender, age, comorbidities, records of previous vaccinations and test results, etc. It can also follow supply of medicines and other medical requirements, planning for patient load, evaluate test center data and assist in collaboration in the areas of research and development.

5. 3D Printing: 3D printing is one more technological tool which has shown promising results in the healthcare sector (The New Indian Express, 2020). Orthopedic devices and implants along with 3D bio printing of skin tissue for burn or accident victims, or a prosthetic limb for handicapped patients. 


\section{Methods}

\section{Artificial intelligence}

In this paper, the researchers are mainly focusing on artificial intelligence as a solution provider for healthcare professionals amid COVID-19 pandemic. Artificial intelligence has the capability to deal with huge amounts of data without creating panic in the whole system (Salman, et al., 2020). This technology is a combination of human intelligence with creative technical solution (Joshi \& Morley, 2019). During this pandemic time, there is a need of fast processing system with effective solutions. If used diligently AI has the capability to overcome human speed, it can provide solution for cluster of cases simultaneously (Bharti, 2020). The impact of artificial intelligence is from detection of patients to vaccine formation. It is providing a 360-degree effective solution to healthcare professionals. The researchers have performed a systematic literature review on the application of artificial intelligence in dealing with COVID19 problems.

\section{Table 2}

\begin{tabular}{|c|c|l|}
\hline S. No. & \multicolumn{1}{|c|}{ Author } & \multicolumn{1}{|c|}{ Argument for artificial intelligence } \\
\hline 1 & (Alimadad, et al., 2020) & $\begin{array}{l}\text { The automated diagnosis system based on } \\
\text { artificial intelligence and machine learning } \\
\text { not only helps in speedy diagnosis, but it will } \\
\text { also protect health workers to come in direct } \\
\text { contact with the COVID-19 patients. }\end{array}$ \\
\hline 2 & (Shi, et al., 2020) & $\begin{array}{l}\text { Artificial intelligence-based image } \\
\text { acquisition can help to automate the } \\
\text { scanning procedure. } \\
\text { It will also provide best protection to } \\
\text { imaging technicians because they do not } \\
\text { have to meet the patients. } \\
\text { It will improve the work efficiency by } \\
\text { accurate and proper delineation of infection } \\
\text { in X-ray and CT images. }\end{array}$ \\
\hline 3 & (Jamshidi, et al., 2020) \\
& $\begin{array}{l}\text { The authors have argued that the major } \\
\text { advantage of artificial intelligence is } \\
\text { acceleration in the pace of diagnosis and } \\
\text { treatment of patients. } \\
\text { With application of artificial intelligence, the } \\
\text { experts can analyse huge datasets. }\end{array}$ \\
\hline
\end{tabular}




\begin{tabular}{|c|c|c|}
\hline 4 & (Rahmatizadeh, et al., 2020) & $\begin{array}{l}\text { The authors have suggested a three-stage } \\
\text { model with components-input, process, and } \\
\text { output. The input includes clinical data, } \\
\text { paraclinical data, personalized medicine, and } \\
\text { epidemiologic data. Artificial intelligence } \\
\text { based neural network has been used. It is } \\
\text { helpful in diagnosis, treatment, management, } \\
\text { and prognosis. }\end{array}$ \\
\hline 5 & (Bullock, et al., 2020) & $\begin{array}{l}\text { The impact of artificial intelligence has been } \\
\text { discussed from three different perspectives } \\
\text { which include molecular perspective, } \\
\text { clinical perspective, and societal } \\
\text { perspective. From molecular perspective } \\
\text { artificial intelligence can be used to estimate } \\
\text { the structure of SARS-CoV-2 related } \\
\text { proteins. It proposed new compounds for } \\
\text { treatment of virus. } \\
\text { From clinical perspective, artificial } \\
\text { intelligence helps in fast diagnosis, use of } \\
\text { non-invasive devices can help in tracking the } \\
\text { disease evolution. AI is also helpful in } \\
\text { generating patients' outcome reports by } \\
\text { tracking multiple input data. } \\
\text { From the societal perspective, AI can be } \\
\text { helpful in judging out the evolution of } \\
\text { pandemic between different regions, it will } \\
\text { also help in forecasting the number of cases. }\end{array}$ \\
\hline 6 & (Lalmuanawma, et al., 2020) & $\begin{array}{l}\text { It is stated that artificial intelligence is } \\
\text { helpful in screening of patients. } \\
\text { In different countries governments are using } \\
\text { artificial intelligence and machine learning }\end{array}$ \\
\hline
\end{tabular}




\begin{tabular}{|c|c|c|}
\hline & & $\begin{array}{l}\text { based apps for contact tracing so that they } \\
\text { can trace the virus affected persons. } \\
\text { Artificial intelligence is also used in } \\
\text { prediction, forecasting and checking out the } \\
\text { drugs and vaccination for COVID-19 } \\
\text { disease. }\end{array}$ \\
\hline 7 & (Ozsahin, et al., 2020) & $\begin{array}{l}\text { The authors discussed chest radiography } \\
\text { approach to detect COVID-19 cases. In } \\
\text { comparison to laboratory-based approach, } \\
\text { the chest radiography approach is useful in } \\
\text { detection of COVID-19 patients. }\end{array}$ \\
\hline 8 & (Salman, et al., 2020) & $\begin{array}{l}\text { The authors have discussed the application } \\
\text { of deep learning technique based on artificial } \\
\text { intelligence to detect the COVID-19 } \\
\text { patients. Deep learning technique is } \\
\text { detecting the COVID-19 disease using high } \\
\text { resolution X-rays and it is reducing the } \\
\text { workload of medical healthcare } \\
\text { professionals. }\end{array}$ \\
\hline 9 & (Sharma \& Dyreson, 2020) & $\begin{array}{l}\text { The authors argue that there is shortage of } \\
\text { test kits for detecting COVID-19 patients. } \\
\text { Residual attention network based on } \\
\text { artificial intelligence can be useful for } \\
\text { detecting the COVID-19 cases. Chest X-Ray } \\
\text { images can be used to detect COVID-19 } \\
\text { cases and further it can collaborate with } \\
\text { other testing method to produce a desired } \\
\text { outcome. }\end{array}$ \\
\hline 10 & (Da Silva, et al., 2020) & $\begin{array}{l}\text { The authors have discussed the application } \\
\text { of forecasting artificial intelligence } \\
\text { techniques and models to deal with } \\
\text { continuously increasing COVID-19 cases in } \\
\text { America and Brazil. This technique helps in }\end{array}$ \\
\hline
\end{tabular}




\begin{tabular}{|c|c|c|}
\hline & & $\begin{array}{l}\text { forecasting the COVID-19 cases well in } \\
\text { advance as per time series. }\end{array}$ \\
\hline 11 & (Vaishya, et al., 2020) & $\begin{array}{l}\text { The study signifies that artificial intelligence } \\
\text { can mimic the human intelligence and it will } \\
\text { help in overall control of COVID-19 disease. } \\
\text { AI will help in detecting and development of } \\
\text { vaccination. Through artificial intelligence a } \\
\text { big chuck of data can be analysed. It will } \\
\text { help in proper screening, detection and } \\
\text { tracking of current patients and future } \\
\text { patients. }\end{array}$ \\
\hline 12 & (Jat \& Singh, 2020) & $\begin{array}{l}\text { The authors have argued about the role of } \\
\text { artificial intelligence equipped drones in big } \\
\text { data analytics and improving the overall } \\
\text { efficiency of the system. Artificial } \\
\text { intelligence-based network connectivity can } \\
\text { improve the overall efficiency of the system. }\end{array}$ \\
\hline 13 & (Kumar, et al., 2020) & $\begin{array}{l}\text { The authors have suggested that artificial } \\
\text { intelligence and Internet of things } \\
\text { collaborative framework can help in } \\
\text { providing solution of COVID-19 problem. } \\
\text { The potential solution of challenges faced by } \\
\text { health care workers can be found through } \\
\text { effective usage of technology in the form of } \\
\text { collaborative Framework }\end{array}$ \\
\hline 14 & (Yu, et al., 2020) & $\begin{array}{l}\text { The researchers have argued that artificial } \\
\text { intelligence-based algorithms have the } \\
\text { capability to reduce the workload of } \\
\text { healthcare professionals by provide help in } \\
\text { drug development. It is also helping in } \\
\text { epidemic forecast and clinical diagnosis. }\end{array}$ \\
\hline 15 & (Soldani, 2020) & $\begin{array}{l}\text { Artificial intelligence is leading technology } \\
\text { for data analysis and image capturing and it }\end{array}$ \\
\hline
\end{tabular}




\begin{tabular}{|c|c|c|}
\hline & & $\begin{array}{l}\text { can help in fighting pandemic in real } \\
\text { scenario. }\end{array}$ \\
\hline 16 & (Leite, et al., 2020) & $\begin{array}{l}\text { The researchers have discussed telemedicine } \\
\text { and e-healthcare support in dealing with } \\
\text { COVID-19 patients. AI can play a leading } \\
\text { role when it comes to telemedicine. }\end{array}$ \\
\hline 17 & (Bharti, 2020) & $\begin{array}{l}\text { The researcher has discussed telemedicine. } \\
\text { She argued that artificial intelligence based } \\
\text { powered conversational Chatbot can be an } \\
\text { effective solution provider amid COVID-19 } \\
\text { pandemic. }\end{array}$ \\
\hline 18 & (Chen, et al., 2020) & $\begin{array}{l}\text { The study reveals that key role of artificial } \\
\text { intelligence is in image inspection. The } \\
\text { image inspection can be CT image } \\
\text { inspection or chest X-ray image inspection. } \\
\text { It is also useful in organ recognition, } \\
\text { infection region segmentation and disease } \\
\text { classification. }\end{array}$ \\
\hline 19 & (Jiang, et al., 2020) & $\begin{array}{l}\text { The researchers have used AI base } \\
\text { framework with predictive analytics } \\
\text { capabilities to provide real patient data and } \\
\text { help in clinical decision making. }\end{array}$ \\
\hline 20 & (Bhaskar, et al., 2020) & $\begin{array}{l}\text { Telemedicine is the need of hour to handle } \\
\text { the impact of pandemic. Artificial } \\
\text { intelligence and robotics can play an } \\
\text { important role in providing telemedicine to } \\
\text { the healthcare workers to deal with COVID- } \\
19 \text { problem. }\end{array}$ \\
\hline
\end{tabular}

Table 2 - Literature review on usage of artifical intelligence in medical treatments

The above literature review suggested that artificial intelligence can be an effective solution in all the fields of healthcare management in the fight against COVID-19. Artificial intelligence technology is a contributing force in image processing through chest X-ray, detection through social distancing app, essential component in image processing, data mining and natural language processing. It can mimic the human intelligence but cannot replace it. The mimic of human intelligence can be helpful in vaccination against COVID-19 disease. The framework 
derived from artificial intelligence in the form of deep learning and residual network diagram can be helpful in providing insights for fast detection of COVID-19 patients. It will promote fast detection of COVID-19 patients. It can be said that from the point of view of healthcare workers this is an apt technology to work with in pandemic situation.

A model has been developed as shown in figure 4 The model is justifying the usage of artificial intelligence leading to small-, medium- and long-term gains for society and healthcare professionals. The short-term gains of artificial intelligence are fast and efficient tracking of disease and fast diagnosis with proper safety of healthcare professionals (Sun, et al., 2020; McCall, 2020). The medium-term gains include an active support in making vaccination and implementation of public health interventions (Pacheco Rocha, et al., 2019). The long-term gains include that artificial intelligence can be further tested by researchers in international organizations to check its application in combating COVID-19. Artificial intelligence clubbing with other technology 4.0 tools can be helpful in building smart and healthy cities (Bragazzi, et al., 2020). Artificial intelligence has the capability to come out as a solution in long term, but researchers need to think on its combination with other technologies as internet of things, robotics, or $3 \mathrm{D}$ printing.

\section{Figure 3}

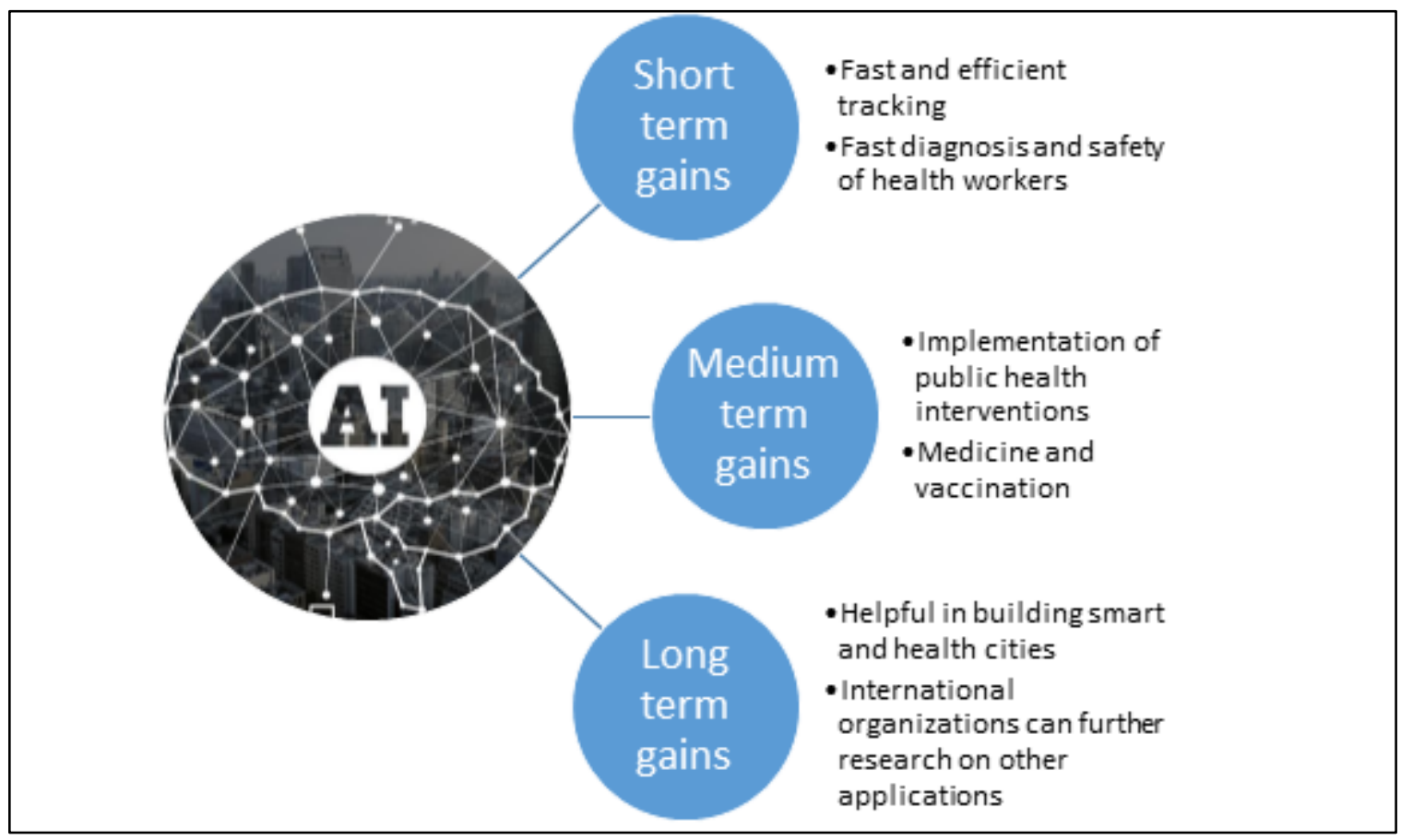

Figure 3 - Medical gains based on artifical intelligence

\section{Artificial intelligence for telemedicine}

The impact of COVID-19 pandemic in increasing around the world. The healthcare industry is facing the challenge to provide cost-effective medicine to the population. A large group of people is affected by corona virus problem. The medicine should be in reach of the population so that chaos can be avoided in future. Telemedicine can be an effective solution because nowadays many people are using internet and smart phones. The telemedicine can relate to their smartphone apps. In this manner it can reach many people. While preparing vaccination and medicine, the healthcare industry needs to deal with large datasets of diseased population (Bhaskar, et al., 2020). The international community is trying to offer solution for COVID-19 diagnosis, treatment and forecasting based on data driven tools and pooled data sets (big data). 
Artificial intelligence can provide effective solution in the form of algorithms which can be useful in processing big amounts of data (Kumar \& Kalse, 2021). All the industries, either in manufacturing or service sector, are adopting digitization to achieve economies of scale (Kumar \& Ayedee, 2018; Kumar \& Pandey, 2018) and provide effective solutions to clients. Healthcare industry should also start using artificial intelligence-based algorithms in least developed countries. It has been argued that artificial intelligence-based applications can save more than $\$ 150$ billion annually in United States by 2026 (Accenture, 2020). Amid this pandemic the healthcare industry needs to work on feasible solution which can limit the usage of human interaction. The usage of electronic gadgets is high among healthcare workers and citizens. Artificial intelligence-based medicine can act as a bridge between healthcare workers and citizens.

The physical interaction of patients and doctors must be taken care of so that doctors can protect themselves. Artificial intelligence-based telemedicine can be helpful for the doctors to provide much needed cure and care to patients from remote location (Leite, et al., 2020). The various governments and healthcare organizations are appealing to people that they should stay at home unless it is very urgent to visit doctors in person. Telepath based medicine will minimize visiting doctors physically and it will also save the lives of healthcare workers. The implementation of telemedicine is difficult but once implemented it can serve the purpose of dealing with large number of patients (Hoffman, 2020). The major hurdle in the implementation of telemedicine using artificial intelligence is the access to technology and internet in remote areas. It is true that electronic gadgets are in use, but those electronic gadgets are not used by people living in less developed countries and rural regions. COVID-19 is equally affecting the people living far below poverty line. Even if the healthcare industry is thinking of providing effective solution of COVID-19 problem in the form of artificial intelligence-based telemedicine, the industry needs to think about the accessibility by the people who are not using technology. The implementation of telemedicine should not stop because all the population do not have the knowledge of technology usage. The users of telemedicine will come in the second phase, after the problems of the healthcare professionals in retrieving the data from a large data set are acknowledged.

\section{Results}

Based on current literature review, certain findings can be observed. The different components of technology 4.0 can be handy in dealing with COVID-19 problem and safeguarding the healthcare workers, too. Artificial intelligence is an important and prolific component of the health care industry which is helpful to diagnosis and other medical services. Artificial Intelligence is proving to be a vital transformational tool for tracking the pandemic with a better speed and efficiency than humanly possible. The following are the recommendations of this study:

- Usage of Artificial Intelligence for understanding and implementation of medication needs, and vaccination schedule follow-up must be explored. This will ensure outreach to everyone, in time and with better results and effective use of the cost incurred.

- Radiology, Screening, Psychiatry, Primary Care, Disease Diagnosis, Telemedicine, Electronic health records, Drug Interactions and Creation of new drugs are few of the multiple implementations of Artificial Intelligence in the healthcare sector. As the healthcare sector identifies more and more usage of AI and machine learning, medical practitioners might get more time for giving more personalized care for their patients (Hamilton, 2020). This will bring more human touch to the healthcare sector. It is imperative that the governments in developing and developed countries prioritize this while planning the spending of the public finances. 
- The next big trend in the healthcare sector is going to be patient engagement with more personalized medical service with the help of Artificial Intelligence (Kumar \& Kalse, 2021). Telemedicine for the public healthcare system, patient data security, ecommerce and reduction of medical costs should be the areas of focus of the healthcare sector.

- The early adoption of Artificial Intelligence to create a foundation of digital healthcare should be made a priority. Finding ways of combining emerging technologies to tackle the enormous challenges posed by the pandemics is of great importance and urgency.

\section{Conclusion}

Based on above discussion, it can be concluded that technology 4.0 is the future for healthcare industry including curing COVID-19 pandemic. There are different components of technology 4.0, artificial intelligence-based algorithms and frameworks can help working faster than human. The medical industry needs to safeguard their own healthcare workers and provide solution for growing number of medical patients. Artificial intelligence can work in short term by providing effective diagnosis and tracking; medium term and longer term by providing medicine vaccination. Telemedicine can be supported by artificial intelligence-based technology in analyzing large of data sets. So, the healthcare industry in future should invest more in artificial intelligence-based medicine and treatment to achieve economies of scale.

\section{Limitations and scope of future research}

The prime focus of this research work is on one component of technology 4.0, i.e., artificial intelligence. The future research can focus on other components of technology 4.0. Another limitation of this research is that it is primarily focusing on the impact on artificial intelligence in diagnosis. The future researchers can explore the usage of artificial intelligence in vaccine formation and aspects of dealing with patients during COVID-19. This research work is based on previous published research articles and internet resources. Future researchers can do a primary study by preparing a structured questionnaire and test their hypothesis for generalizability of the study. More research work should be done in the field of artificial intelligence, extended reality, and other upcoming innovations like blockchain and quantum computing for a better and safe world and creation of smart and healthy cities.

\section{References}

Accenture, 2020. Artifical Intelligence (AI): Healthcare's new nervous system. [Online] Available at: https://www.accenture.com/au-en/insights/health/artificial-intelligencehealthcare

Alimadad, A. et al., 2020. Artificial intelligence and machine learning to fight COVID-19. Physiol Genomics, Volume 52, pp. 200-202.

Anon., n.d.

Bharti, U., 2020. Medbot: Conversational Artificial Intelligence Powered Chatbot for Delivering Tele-Health after COVID-19. s.1., Proceedings of the Fifth International Conference on Communication and Electronics Systems (ICCES 2020).

Bhaskar, S. et al., 2020. Designing futuristic telemedicine using artifical intelligence and robotics in the COVID-19 era. Frontiers in Public Health, Volume 8, pp. 1-7.

Blumstein, G., 2019. Research: How Virtual Reality Can Help Train Surgeons. [Online] Available at: https://hbr.org/2019/10/research-how-virtual-reality-can-help-train-surgeons [Accessed 5 May 2021]. 
Bragazzi, N. L., Dai, H., Damiani, G. \& Wu, J., 2020. How Big Data and Artificial Intelligence Can Help Better Manage the COVID-19 Pandemic. International Journal of Environmental Research and Public Health, Volume 17, p. 3176.

Bullock, J. et al., 2020. Mapping the landscape of Artificial Intelligence applications against COVID-19. [Online]

Available at: https://arxiv.org/pdf/2003.11336.pdf

[Accessed 6 November 2020].

Da Silva, R. G., Ribeiro, M. H. D. M., Mariani, V. C. \& Coelho, L. d. S., 2020. Forecasting Brazilian and American COVID-19 cases based on artificial intelligence coupled with climatic exogenous variables. Chaos, Solitons \& Fractals, Volume 139.

Hamilton, I. A., 2020. Google's DeepMind created an AI for spotting breast cancer that can outperform human radiologists. [Online]

Available at: https://www.businessinsider.in/science/news/googles-deepmind-created-an-aifor-spotting-breast-cancer-that-can-outperform-humanradiologists/articleshow/73070327.cms

[Accessed 13 November 2020].

Hoffman, D. A., 2020. Increasing access to care: telehealth during COVID-19. Journal of Law and the Biosciences, 7(1).

Chen, J. et al., 2020. A Survey on Applications of Artificial Intelligence in Fighting Against COVID-19. [Online]

Available at: https://arxiv.org/pdf/2007.02202.pdf

[Accessed 9 September 2020].

Jamshidi, M. et al. (2020). Artificial Intelligence and COVID-19: Deep Learning Approaches for Diagnosis and Treatment. IEEE Access, 8(1), pp. 109581-109595.

Jat, D. S., \& Singh, C. (2020). Artificial Intelligence-Enabled Robotic Drones for COVID-19 Outbreak. In: Intelligent Systems and Methods to Combat Covid-19. pp. 37-46.

Javaid, M. et al. (2020). Industry 4.0 technologies and their applications in fighting COVID19 pandemic. Diabetes \& Metabolic Syndrome: Clinical Research \& Reviews, 14(4), pp. 419422. doi: 10.1016/j.dsx.2020.04.032.

Jiang, X. et al. (2020). Towards an Artificial Intelligence Framework for Data-Driven Prediction of Coronavirus Clinical Severity. Computers, Materials \& Continua, 63(1), pp. 537-551. doi:10.32604/cmc.2020.010691.

Joshi, I., \& Morley, J. (2019). Artificial Intelligence: How to get it right. Putting policy into practice for safe data-driven. London, United Kingdom: NHSX.

Kumar, A., \& Ayedee, N. (2018). Social Media tools for business growth of SMEs. Journal of Management, 5(3), pp. 137-142.

Kumar, A., \& Ayedee, N. (2021). An Interconnection between COVID-19 and Climate Change Problem. Journal of Statistics and Management Systems, pp. 1-21.

https://doi.org/10.1080/09720510.2021.1875568

Kumar, A., \& Kalse, A. (2021). Usage and adoption of artificial intelligence in SMEs. Materials Today: Proceedings.

https://doi.org/10.1016/j.matpr.2021.01.595 (Article in press). 
Kumar, A., \& Pandey, A. (2018). Usage of social media as an integrated marketing tool in business. Journal of Management, 5(3), pp. 123-128.

Kumar, A., Syed, D. A. A., \& Pandey, D. A. (2020). How Adoption of Online Resources Can Help Indian SMEs in Improving Performance during COVID-19 Pandemic. Test Engineering and Management, 83(83), pp. 3394-3400.

https://www.testmagzine.biz/index.php/testmagzine/article/view/13331/10168.

Kumar, M. S., Raut, D. R. D., Narwane, D. V. S., \& Narkhede, D. B. E. (2020). Applications of industry 4.0 to overcome the COVID-19 operational challenges. Diabetes \& Metabolic Syndrome: Clinical Research \& Reviews, 14(5), pp. 1283-1289.

https://doi.org/10.1016/j.dsx.2020.07.010.

Kumar, S., Raut, R. D., \& Narkhede, B. E. (2020). A proposed collaborative framework by using artificial intelligence-internet of things (AI-IoT) in COVID-19 pandemic situation for healthcare workers. International Journal of Healthcare management, 13(4), pp. 337-345.

https://doi.org/10.1080/20479700.2020.1810453.

Lalmuanawma, S., Hussain, J., \& Chhakchhuak, L. (2020). Applications of machine learning and artificial intelligence for Covid-19 (SARS-CoV-2) pandemic: A review. Chaos, Solitons \& Fractals, Volume 139.

https://doi.org/10.1016/j.chaos.2020.110059.

Leite, H., Hodgkinson, I. R., \& Gruber, T. (2020). New development: 'Healing at a distance'telemedicine and COVID-19. Public Money \& Management, 30(6), pp. 483-485.

https://doi.org/10.1080/09540962.2020.1748855

Mabiyan, R. (2018). How artificial intelligence can help transform Indian healthcare.

[Online]

Available at: https://health.economictimes.indiatimes.com/news/health-it/how-artificialintelligence-can-help-transform-indian-healthcare/64285489

[Accessed 13 November 2020].

McCall, B. (2020). COVID-19 and artificial intelligence: Protecting health-care workers and curbing the spread. Lancet Digital Health, Volume 2, pp. 166-67.

https://doi.org/10.1016/S2589-7500(20)30054-6

Neto, R. d. C. S., Maia, J. S., Neiva, S. d. S., \& Scalia, M. D. (2020). The fourth industrial revolution and the coronavirus: a new era catalyzed by a virus. Research in Globalization, 2(2020), pp. 1-7.

https://doi.org/10.1016/j.resglo.2020.100024

Ozsahin, I. et al. (2020). Review on Diagnosis of COVID-19 from Chest CT Images Using Artificial Intelligence. Machine Learning and Network Methods for Biology and Medicine 2020, 2020(1), pp. 1-10.

https://doi.org/10.1155/2020/9756518

Pacheco Rocha, N. et al. (2019). Smart Cities and Healthcare: A Systematic Review. Technologies , 7(58).

Porter, S. (2020). The impact of COVID-19 on health tech adoption in the UK. [Online] Available at: https://www.healthcareitnews.com/news/emea/impact-covid-19-health-tech- 
adoption-uk

[Accessed 13 November 2020].

Rahmatizadeh, S., Valizadeh-Hagh, S., \& Dabbagh, A. (2020). The Role of Artificial Intelligence in Management of Critical COVID-19 Patients. Journal of Cellular \& Molecular Anesthesia, 5(1), pp. 16-22.

https://doi.org/10.22037/jcma.v5i1.29752.

Salman, F. M. et al. (2020). COVID-19 Detection using Artificial Intelligence. International Journal of Academic Engineering Research (IJAER), 4(3), pp. 18-25.

Sharma, V., \& Dyreson, C. (2020). COVID-19 Screening Using Residual Attention Network an Artificial Intelligence Approach. [Online]

Available at: https://arxiv.org/pdf/2006.16106.pdf

[Accessed 6 November 2020].

Shi, F. et al. (2020). Review of Artificial Intelligence Techniques in Imaging Data

Acquisition, Segmentation and Diagnosis for COVID-19. IEEE Reviews, 14(2021), pp. 4-15.

doi: 10.1109/RBME.2020.2987975

Singh, A. K., \& Misra, A. (2020). Impact of COVID-19 and comorbidities on health and economics: Focus on developing countries and India. Diabetes \& Metabolic Syndrome:

Clinical Research \& Reviews, pp. 1625-1630.

doi: 10.1016/j.dsx.2020.08.032.

Singh, R. P., Javaid, M., Haleem, A., \& Suman, R. (2020). Internet of things (IoT)

applications to fight against COVID-19 pandemic. Diabetes \& Metabolic Syndrome: Clinical Research \& Reviews, 14(4), pp. 521-524.

https://doi.org/10.1016/j.dsx.2020.04.041.

Soldani, D. D. (2020). Fighting COVID-19 with 5G enabled Technologies. Huawei Technologies, 23 April , pp. 1-14.

Sun, K., Chen, J., \& Viboud, C. (2020). Early epidemiological analysis of the coronavirus disease 2019 outbreak based on crowdsourced data: A population-level observational study. Lancet Digital Health, 2(4), pp. 201-208.

https://doi.org/10.1016/S2589-7500(20)30026-1

Tenchov, R. (2021). Understanding the nanotechnology in COVID-19 vaccines. [Online] Available at: https://www.cas.org/blog/understanding-nanotechnology-covid-19-vaccines

The New Indian Express, 2020. Tech Tonic: Medical innovations changing healthcare sector. [Online]

Available at: https://www.newindianexpress.com/magazine/2020/sep/06/tech-tonic-medicalinnovations-changing-healthcare-sector-2192091.html

[Accessed 13 November 2020].

Vaishya, R., Javaid, M., Khan, I. H., \& Haleem, A. (2020). Artificial Intelligence (AI) applications for COVID-19 pandemic. Diabetes \& Metabolic Syndrome: Clinical Research \& Reviews, 14(4), pp. 337-339.

https://doi.org/10.1016/j.dsx.2020.04.012.

WHO, 2013. Nanotechnology and human health: Scientific evidence and risk governance, Bonn, Germany. Copenhagen: Report of the WHO expert meeting 10-11 December 2012. 
World Health Organization, 2020. Coronavirus disease (COVID-19). [Online] Available at: https://www.who.int/docs/default-source/coronaviruse/situationreports/20201012-weekly-epi-update-9.pdf

[Accessed 13 November 2020].

World Health Organization, 2021. WHO Coronavirus (COVID-19) Dashboard. [Online] Available at: https://covid19.who.int/

Yu, P., Xia, Z., Fei, J., \& Jha, S. K. (2020). An Application Review of Artificial Intelligence in Prevention and Cure of COVID-19 Pandemic. Computers, Materials \& Continua, 65(1), pp. 743-760.

doi:10.32604/cmc.2020.011391 